\title{
Learning style preferences of Kurdish graduate students at the Language Centre
}

\section{Soran Karim Salim}

Received: Jul17, 2017

Reviewed: Mar 12, 2018

Accepted: Mar20, 2018

\begin{abstract}

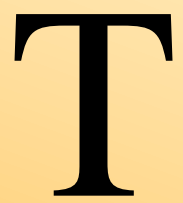

his study investigates the students' learning styles preferences and their implications on the teaching and learning as well as the designs and selection of the text books. A total of 45 graduate students, taking a course called 'English Proficiency Course' at the Language Centre/ Salahaddin University, participated in the study. The students, later, might need English language for academic purposes across different fields of study, namely, higher education in Kurdistan. The participants were asked to choose the styles from the VARK questionnaire. Then the data was collected. The outcomes of which were analysed into some of the major Learning Styles such as 'visual, audio, read/write and kneithetic/tactile' preferences. An implication of this study is that the teaching style should be matched to students' learning style and that the materials, tools and teaching books should also suit students' learning preferences.

Keywords: Learning style preferences, Graduate, Visual, Aural, Read/write, Kinesthetic

\section{Recommended citation:}

Salim, S.K. (2018). Learning style preferences of Kurdish graduate students at the Language Centre. International Journal of Kurdish Studies 4 (2), 309 - 321.doi: 10.21600/ijoks.454430

\footnotetext{
${ }^{1}$ Language Centre, Salahaddin University.E-mail: soran.senior@yahoo.com
} 


\section{INTRODUCTION}

Learners usually gain and process information in different ways: by hearing and seeing, acting and reflecting, analysing and visualizing and thinking logically. Learning styles (henceforth LSs) play an important role in learners' learning process. Therefore, the concept of learning style has received substantial attentions in the literature. The present essay provides some useful definitions of LSs and then reveals some of the major LSs such as visual, auditory, kinaesthetic and tactile, forwarded by advantages and disadvantages (if any) of each style in a systematic way. In the next section, various research results can be presented on LSs. Finally, the paper ends with some findings, discussions and conclusions with the list of references for further reading.

\section{THE THEORIES AND CONCEPTS OF LEARNING STYLES}

Traditionally, L2 classes tend to focus on vocabulary, grammar, reading, speaking or listening skills. Yet 'we should bear in mind, that communication [...] is inseparable and interconnected' (Kozhevnikova, 2014). If teachers want to make learners speak, they will need to let them know which LSs they prefer. LSs are considered as the most influential factors that aid learners learning a foreign language/second language (henceforth only L2). Learners often dominate the general approaches such as auditory, visual, global or analytical in learning new languages or any other disciplines. Those styles are 'the overall patterns that give general directions to learning behaviour' (Cornett, 1983 as cited in Oxford, 2001).

The theory of LS (NB: LSs as plural and LS as singular) is relatively recent, and became apparent in the seventies (Williamson \& Watson, 2006). LS theory suggests that individuals present a preference for typical learning behaviours that help the individuals to get success in their learning process (Van Zwanenberg et al., 2000). Thus, LSs are usually exhibited by students. Then what is occurring is an underlying mismatch between the preferred styles of teachers with that of learners. Therefore, it is always significant for teachers to be aware of their students' preferred styles. However, learners forget which styles suit them the most. Sometimes students will not take the methods and/or strategies which are recommended by a teacher. Consequently, teachers need to pinpoint their students' preferred LSs. In this way, the teaching styles will be well matched with the LSs (Zhou, 2011). In turn, oblige educational authorities to design classroom materials that match and respond directly to those preferences and assist learners to have a better performance in language skills (Sahragard and Mallahi, 2014).

Additionally, LSs often have advantages for identifying feasible learning activities to increase satisfaction during obtaining new information. Furthermore, they are means for recognising weak areas which might be improved for more successful learning procedures. This idea is supported by a review of nineteen studies in the field of LSs and learning activities (Hayes \& Allison, 1996). In their study, twelve out of nineteen studies were supported by the hypothesis that matching style has had an affirmative influence on learning performance. 


\section{Definitions of Learning Styles}

To understand more concepts of LSs, one should know that what the learning style is. LSs, which are students' preferred approach of language learning have been given a great attention and have been the focus of numerous L2 studies since the 1980s.

There are several useful definitions for LSs in the literature. In the late eighties LS was defined by Reid (1987: 89) as 'variations among learners in using one or more senses to understand, organize, and retain experience'. Another definition is given by Spolsky (1989) as 'identifiable individual approaches to learning situations' (p.109). More recently, Reid (1995, as cited in Dörnyei, 2005: 121; and Peacock, 2001: 2; Sahragard \& Mallahi, 2014: 1612) offers a standard definition of LSs. She defines as an 'individuals' natural, habitual, and preferred way(s) of absorbing, processing, and retaining new information and skills'. Similarly, Pritchard (2008), states that LSs are 'preferred way[s] of learning and studying' (p.42). In fact, nowadays, Reid's definition is considered as the most accepted one. In consequence, learners may use visual pictures instead of texts; working in groups rather than working alone; or gaining knowledge in a structured manner not in an unstructured way.

The term 'learner preference' is used to refer to the 'conditions, encompassing environmental, emotional, sociological and physical conditions' in which learners will opt for if they have the opportunity to make a choice (Pritchard, 2008: 43). This choice has a significant role in learning progress. It may relate more to 'cognitive preference' as well.

Another related term to LS is 'cognitive styles'. It is to do with 'cognition' which is considered as broader aspect of LS. The study of cognition analyses the way in which people categorize their knowledge according to the way individuals interpret the world, for example, dealing with certain approaches which are based on mental schemes or thoughts like problemsolving and reasoning (Mortimore, 2003: 6-7). In the light of this, one accepted definition of 'cognitive styles' is that 'cognitive styles' are 'individuals preferred and habitual modes of preserving, remembering, organizing, processing, and representing information' (Dörnyei, 2005: 125). In particular, LS is simply the type of strategy employed when learners' cognitive style is applied to a learning environment.

\section{MAIN CONCEPTUAL ISSUES OF LEARNING STYLES}

Let's examine some common issues in the conceptualization of LSs. Firstly, what differentiates LSs from learning strategies? The two terms are not mutually exclusive because they are both typical approaches that learners utilize in learning a target language. Snow et al. (1996) state that the only difference between the two concepts rests in their breadth and stability, that is, style is being a 'strategy used consistently across a class of tasks' or activities (p.281). To be more precise, styles are described as stable and unconscious preferences (Valeo, 2000: 8). The disagreement with this claim, Pritchard (2008) adds that styles are not fixed traits that learners will often display. Students are capable of adapting different styles in different circumstances. Many learners use one or more styles which are preferred over the 
others. Usually, the general problem in the LS field is that the LS concept is used as a 'portmanteau term for a range of individual difference[s]...among other things[;] learning preferences, learning strategies, approaches to studying and cognitive style (Sadler-Smith, 2001: 293). On balance, the literature on LSs uses the terms 'learning style, cognitive style, personality type, sensory preference, modality, and others rather loosely and often interchangeably' (Ehrman et al., 2003: 314, italics in original).

There are plentiful of models or schemes of LSs that have been proposed over the years which are vying for prominence in broadest sense including numerous articles and dozens of books. Coffield and colleagues (2004) reported and described 71 different theories of LS in present circulation in the UK, but authors did not claim that their list was exhaustive (Pashler et al., 2009). Among them, Kolb's (1999) learning style inventory (LSI), Honey \& Mumford's (1992) learning style questionnaire (1991), Riding's (1991) cognitive style analysis (CSA) and so forth.

A few well known examples of these theories in present use include Kolb's (1981; 1984, as cited in Flowerdew \& Shehadeh, 2008 and Dörnyei, 2005: 129-131) experimental learning theory which consists four learning modes (concrete/abstract and active/reflexive). Kolb stated that, to some extent, almost every individual learner uses each learning mode but also has the inclination to learn through either 'active experimentation' or 'reflexive observation'. These LS preferences are explained by Kolb (1984) as to four-way typology (i.e. divergent, assimilative, convergent and accommodative).

However, the preferred scheme may be different for L2 learning. Ehrman \& Oxford (1990) referred to nine main style elements relevant to L2 learning. Some of them are based on psychological issues, though Oxford (2001) condensed and described only four dimensions which are likely to be influential among linguists for L2 learning: sensory preferences, personality types, desired degree of generality, and biological differences. 'Sensory preferences' can be sub-divided into four items: visual, auditory, kinaesthetic and tactile. The second 'personality types' also consists of four elements: extroverted versus introverted; intuitive random versus sensing-sequential; thinking versus feeling and closureoriented/judging versus open/perceiving (this type usually known as psychological type). The third dimension (=desired degree of generality) divides students into global/holistic and analytical ones. Lastly, the fourth dimension (=biological difference) has something to do with biological factors such as biorhythms, sustenance, and location (ibid: 360-361).

Due to lack of space, only the sensory preference type is illustrated in the following section which is the most popular model that derived from Fleming's (1991) VARK theory. This theory originally classifies learners into four but now most theorists and researchers use three common groups: visual, auditory, and tactile/kinaesthetic (Scott, 2010). It is to be noted that these (sensory preference) criteria are making us less worried, unlike the previous ones mentioned, and can be described clearly by observing learners in the language classrooms. 


\section{Sensory Preferences or VARK}

LSs have been identified under various classification systems. Students may prefer learning by seeing, hearing, or touching. This refers to VARK which is an acronym stands for visual, aural, read/write, and kinaesthetic. VARK for Hawk \& Shah (2007) is the group of instructional preference(s) since it concerns with perceptual senses but it does not address the two senses (e.g. taste and smell) out of five human senses.

Sensory preferences refer to the physical perceptual learning channels that students are the most comfortable with. The following sub-sections illustrate the LSs into more details with that of pros and cons of each in turn.

5.1 Visual learners: L2 learners prefer leaning by seeing and they are good at visualising events and retaining information. Students of this type like to read and obtain substantial information from visual means such as text-based resources (handouts, flashcards) and other verbal sources/or by special information (pictures, and videos) through overhead projectors and data shows (Abu-Assali, 2005; Cohen \& Weaver, 2005; Dörnyei, 2005; Pritchard, 2008).

The advantage of this type is that students can use visual strategies for recalling information and usually take detailed notes in the classroom. These learners are called good language planners and fast learners. (Abu-Assali, 2005; Reid, 2005). However, the disadvantages of visual learners are that learners may need extra time to complete a task. They may not spend sufficient time or pay enough attention to specific details of information. The learners will be more interested in the outer shell rather that actual value of the thing itself. (Reid, 2005: 93).

5.2 Auditory learners: L2 learners prefer learning through listening and speaking. They like the instructor to give verbal instructions. They like to listen to audiotapes, narrative stories. These learners also benefit from the nuances of language, such as listening to tone of voices, pitches, and can understand the central meaning of them. Further, they like to read the text out loud which will help them remember the information (Abu-Assali, 2005; Afitska, 2012; Cohen \& Weaver, 2005; Dörnyei, 2005; Pritchard, 2008). The only drawback is that learners, sometimes, have difficulties in written assignments or tasks (Oxford, 2001).

5.3 Kinaesthetic and tactile learners: L2 learners prefer learning through moving, doing, and touching. They prefer work with tangible objects. Sitting at desks for a long period of time is not for them; they favour to have regular breaks. They learn best by hands-on activities and also use body language when they talk (Abu-Assali, 2005; Afitska, 2012; Dörnyei, 2005).

The benefit of this type is that learners enjoy the actual skill of learning. They will be able to show how they are doing something in real world. However, its drawback is that, students may not be able to pay attention to every detail especially in written contexts. Also they may likely miss some information/instruction if it is presented orally (Reid, 2005:93). 
I would argue that the different sensory preferences are not mutually exclusive. For example, Dörnyei (2005) names successful students who they integrate both visual and auditory styles in an effective way.

\section{EMPIRICAL RESEARCH ON LEARNING STYLES}

There is clear evidence that students score higher on tests when students LSs match with that of teachers (Dunn \& Dunn, 1978, as cited in Abu-Assali, 2005). In Pask's (1976) study, learners seem to be categorised into two groups: holistic and serialistic learners. The former refers to those who choose bits of information within a broader framework. They often like to have a general idea of how things are processed before going into much detail. The latter, however, refers to those who choose narrow method of learning; they are not capable of seeing the large picture as a whole. They might focus on different topics simultaneously. This is why their knowledge might be built consecutively (ibid: 12-13).

\subsection{Reid's (1987) study}

For the purpose of this essay, a great body of literature have been examined on LSs. There are a few research about Arabs. A study which was carried out by Reid (1987) proved that ESL learners varied significantly in their sensory preferences. She stated that Asian students were mainly visual, with Koreans being the most visuals in their learning preference, although they favoured kinaesthetic and tactile as their major LSs. She also evidenced that the LS patterns were similar within the same culture and different across the groups. In other words, culture has a strong impact on LS (Hedge, 2000). These results were revealed by Reid (1987) over 1388 students to a questionnaire in forty-three intensive English language programs in the US, with 154 native speakers at university. The Japanese and Koreans differed significantly from all other groups in their preference. This is because of their cultural background which is usually affecting one's preferred style. Basically, Japan and Korea are high-context culture countries in which they have various rules that control individuals' manners, behaviours and relationships.

In Reid's study Arabic and Chinese students were reported to be 'visual' learners. The Arabic learners were capable of learning four major LSs equally (i.e. visual, auditory, tactile, and kinaesthetic). Meanwhile, in Abu-Assali's (2005) study only visual style was predominant. In Reid's study Japanese students were the least auditory learners, with this result being considerably different from Arabic and Chinese students, who strongly favoured auditory LS. Moreover, Spanish, Thai, Malay students were also strongly auditory, though somewhat less than Arabic and Chinese learners.

The majority of ESL students in Reid's study strongly preferred kinaesthetic style, and the strongest in this domain were Arabic, Spanish, Chinese, Korean and Thai learners. English native speakers were significantly less tactile than other previous learners. Most nonnative English speakers were extremely tactile in their learning preferences. Some cultural groups in the Reid's study have various main perceptual LS preferences. They could learn equally through two or more obviously articulated sensory organs. For instance, Spanish 
speakers were very distinct in their sensory style: they preferred tactile and kinaesthetic as their dominant LSs, with visual and auditory as their lesser LSs.

\subsection{Peacock's (2001) study}

This study investigates Reid's (1987) hypothesis that says: a mismatch between LSs and teaching styles results in learning failure, frustration and demonization. Reid's questionnaire, interviews and tests were used for data collection. In the study a total of 206 EFL students and 46 EFL teachers were participated at City Hong Kong University. The results indicated that students preferred auditory and kinaesthetic styles; and disliked individual and group styles. While, teachers preferred auditory, kinaesthetic and group styles; and disfavoured individual and tactile styles.

Another part of the study was a semi-structured interview that revealed $72 \%$ of the students were frustrated by a mismatch between teaching and LSs; $76 \%$ said that the mismatch influenced their learning; and $81 \%$ of the teachers consented with Reid's hypothesis.

Peacock suggested that 'EFL teachers should teach in a balanced style in order to accommodate [students] different learning styles' (p.1). Moreover, he noted that learners work harder and gain more information both in and outside the classroom when teachers' style matches students' (p.4).

\subsection{Abu-Assali's (2005) study}

Abu-Assali's study was undertaken to test the assumption that there was a difference between students' LS preferences and instructional approaches given by the teachers. A questionnaire was used to collect data from female students $(n=39$, aged between 17-19) from the third female secondary school in United Arab Emirates (UAE). The student's proficiency level varied from pre-intermediate to intermediate. The questionnaire used to be available in students textbooks entitled 'learning style questionnaire'. Basically, this questionnaire is used to identify students LSs; visual, auditory, group, individual, analytic and holistic. The questionnaire consists of thirty-two elements. Students answered the questions by circling one of the options given next to each question (e.g. disagree strongly, disagree, not sure, agree, and strongly agree). Within that, a semi-structured interview was held with six English teachers at the same school. These teachers came from Jordan $(n=3)$, Sudan $(n=2)$, and Egypt $(n=1)$. Instruction was given to students about LSs in general. Then, the results showed that $44 \%$ were visual learners, $28 \%$ were group learners and $12 \%$ fell in analytic group. None of them appear to be the holistic learner. This is not surprising, as Abu-Assali states, since her students performed well through visual aids, especially when she explained items or thoughts via the data show device or overhead projectors (p.56ff). The second largest group was classified as 'group learners' because students felt free to negotiate and work on assigned tasks in groups. 
During the teacher interview Abu-Assali found that most of the teachers had no idea what the concept of LS is. Four of them seemed to predict little information about LSs. They thought that LSs are related to 'teaching-learning processes'. However, the other two teachers talked about LS according to their own knowledge.

\subsection{Kara's (2009) study}

More recently, Kara (2009) confirms all the hypothesis of Reid's and (somewhat) the results of Peacock's study. Her study was conducted through participating 100 (2 ${ }^{\text {nd }}$ year) students in ELT department with twelve teachers in Anadolu University. Again the results were almost similar (with Peacock's study). Both teachers and learners favoured visual and auditory styles. Hence, LSs matched teaching styles. Furthermore, students reported that they felt unhappy and frustrated when their teachers did not teach their preferred LS. Generally, teachers reported that when they noticed a mismatch they would try to change the style through tasks and activities.

\section{Participants and Materials}

The participants of this study were a total of 45 Kurdish graduate students, taking a course called 'English Proficiency Course' at the Language Centre/ Salahaddin University, participated in the study. The students, later, might need English language for academic purposes across different fields of study, namely, higher education in Kurdistan such as MA, MSc or PhD degrees. The participants were asked to choose the styles from the VARK questionnaire.

The only instrument used in this study was a questionnaire. The questionnaire contained the 16 questions of The VARK Questionnaire (online Version 7.1) used for identifying the participants' learning styles. The questions were evenly distributed, so that people who took the test did not know which question belonged to which LS. There were four options available for each question ('a', 'b', 'c' and 'd') and only one option could be selected for each item. However, students were free to choose more than one option for each question that correspond(s) to their preference choice as well.

\section{Procedures}

The questionnaire was distributed and the collected data were analysed using descriptive statistics via Microsoft Excel. The data obtained from the questionnaire was used to support the findings obtained from the questionnaire.

\section{RESULTS AND DISCUSSION}

The results of the Learning Styles Inventory, as presented in Table 1 and 2, exhibited the average learning styles of English proficiency students at the Language Centre/ Salahaddin University. The data indicated that the general tendency of the students' styles were Aural (14.72\%) and Visual (13.71\%), followed by Read/Write (13.24\%). The least preferred style was Kinesthetic/Touch $(10.97 \%)$. 
Table 1. The number of circled answers for the learning styles of students

\begin{tabular}{ccccc}
\hline & a category & b category & c category & d category \\
\hline No. & V & A & R & K \\
\hline 1 & 15 & 29 & 14 & 4 \\
2 & 8 & 5 & 31 & 4 \\
3 & 24 & 11 & 9 & 7 \\
4 & 10 & 14 & 15 & 12 \\
5 & 7 & 18 & 8 & 15 \\
6 & 9 & 8 & 28 & 8 \\
7 & 6 & 21 & 10 & 14 \\
8 & 11 & 11 & 10 & 7 \\
9 & 8 & 8 & 11 & 8 \\
10 & 20 & 7 & 24 & 6 \\
11 & 4 & 12 & 22 & 10 \\
12 & 9 & 10 & 10 & 18 \\
13 & 12 & 6 & 6 & 7 \\
14 & 12 & 12 & 7 & 16 \\
15 & 9 & 8 & 20 & 12 \\
16 & 11 & 17 & 9 & 16 \\
\hline Total: & $\mathbf{1 7 5}$ & $\mathbf{1 9 7}$ & $\mathbf{2 3 4}$ & $\mathbf{1 6 4}$ \\
\hline
\end{tabular}

Table 2. The analysis of the four learning styles in percentage

\begin{tabular}{cccc}
\hline a category & b category & c category & d category \\
\hline $\mathbf{V}$ & $\mathbf{A}$ & $\mathbf{R}$ & $\mathbf{K}$ \\
\hline 8.571429 & 14.72081 & 5.982906 & 2.439024 \\
4.571429 & 2.538071 & 13.24786 & 2.439024 \\
13.71429 & 5.583756 & 3.846154 & 4.268293 \\
5.714286 & 7.106599 & 6.410256 & 7.317073 \\
4 & 9.137056 & 3.418803 & 9.146341 \\
5.142857 & 4.060914 & 11.96581 & 4.878049 \\
3.428571 & 10.6599 & 4.273504 & 8.536585 \\
6.285714 & 5.583756 & 4.273504 & 4.268293 \\
4.571429 & 4.060914 & 4.700855 & 4.878049 \\
11.42857 & 3.553299 & 10.25641 & 3.658537 \\
2.285714 & 6.091371 & 9.401709 & 6.097561 \\
5.142857 & 5.076142 & 4.273504 & 10.97561 \\
6.857143 & 3.045685 & 2.564103 & 4.268293 \\
6.857143 & 6.091371 & 2.991453 & 9.756098 \\
5.142857 & 4.060914 & 8.547009 & 7.317073 \\
6.285714 & 8.629442 & 3.846154 & 9.756098 \\
\hline
\end{tabular}


The findings showed that the average LSs of graduate students who took an English proficiency course were almost equally preferred by the participants respectively. The findings also indicated that aural and visual styles were the top two learning styles preferred by Kurdish students. When in class, it is likely that group activities and instructions via lectures would be welcomed by these students.

The results of this study are in accordance with the findings of Reid's (1987) and Kara's (2009)studies who detected the preferences of all four styles. That is, there were no significant differences of learning styles among Arabic learners. Although in Reid's study Japanese students were the least auditory learners, which is significantly different from Arabic and Chinese learners, who strongly preferred auditory LS. Additionally, Spanish, Thai, Malay students were also strongly auditory, though somewhat less than Arabic and Chinese learners.

For pedagogical implications, it is suggested that instructors should manage their classes, materials and teaching methods to facilitate students with different learning styles in order to develop their English skills and help them achieve their future academic goals. For example, group activities, teamwork projects, and peer reviews are recommended for fostering a collaborative classroom atmosphere which is favoured by teachers and students. Conventional lectures as well as the use of songs and music via various types of media are also agreeable to the aural learners.

Regarding the results of this study, some implications are discussed with the perspective of teaching staff at the Language Centre, learning and teaching English as a foreign language in Kurdistan. As it has been identified that many of the university students are communicative type of learners, there should be a reasonably safe indicator for the general direction to consider in designing text books for Kurdish learners. Many research studies such as (Hayes \& Allison, 1996; Kozhevnikova, 2014; ) claim that learning methods that match with LS preferences lead to academic achievements, more communicative tasks need to be included in the course as most learners in this sample prefer to learn in a communicative way. Hence, Kurdish learners are not exceptional. Therefore, matching style has had a positive influence on learning performance.

Suggested methods preferred by communicative learners as: 1) Learning by watching and listening to native speakers of the target language. 2) Learning by speaking in English with foreigners when there is a chance. 3) Learning by talking to friends and teachers in English. 4) Learning by group conversations. 5) Learning by watching TV in English. 6)

Learning English by hearing the words. Therefore, the textbook designers may need to take into account the aforementioned methods while designing or choosing communicative text books for L2 classes in Kurdistan.

In the light of learning, effective tools to help students listen to native speakers of the target language is to use films and video programs both in classes and outside classrooms. In 
this case, students get familiar with the other contexts, situations, and cultures. Supplementary materials such as short stories should be utilized in reading and writing classes.

Generally, students need to be involved in interactive skills. In order to contribute students to be aware of their own LSs and strengths, inventories of LS and other processes can be utilized.

Some limitations of this study should not be considered. This study aimed at identifying the LSs of English proficiency class at the Language Centre/ Salahaddin University. As such, the results cannot be generalized to all Kurdish learners. It also focused on the four LSs of the VARK model. This type of LS models is directly affected by the surroundings and circumstances; therefore, the results of the students' LSs may change over time and be influenced by the students' interactions with the environment. In addition, some others aspects, such as, psychological factors and cultural influences were not included in the study. Further studies of learning styles in an EFL writing class and demographic and other aspects should be conducted.

\section{CONCLUSIONS}

The purpose of the current study was to identify Kurdish EFL graduate students' types of learning style preferences and their implications on the teaching and learning process. What can be concluded from this paper is that the majority of Kurdish students fall into visual LS others auditory, individual or group LSs. Based on given results, LS is an indicator of how students want to learn. Each individual learner has his/her own preferred way of perception and retention (Zhou, 2011: 73). I personally have become aware of the importance of LSs from my early studies so far. Thinking back on my experience as a learner, I was not taught these LSs explicitly. Additionally, I could successfully recall any LSs wherever it was necessary. So, it is essential for teachers to know and match their styles to that of students', since learners' preferred style can lead success in the language classrooms (Castro \& Peck, 2005: 401).

In particular, Ford \& Chen (2001) claimed to have expressed support for matching LS with teachers teaching style. Peacock (2001) suggested that 'EFL teachers should teach in a balanced style in order to accommodate [students] different learning styles' (p.1). Moreover, he noted that learners work harder and gain more information both in and outside the classroom when teachers' style matches students' (p.4).

In brief, I always agree with Peacock's suggestion (2001:17), that raised awareness of LSs should be part of 'teacher training, development and assessment'. Teachers should be more aware of how to give or integrate tasks and activities that meet students' preferred styles (especially visual and auditory). This means that, knowledge of the LSs of students may help teachers identifying learning problems and they will be able to help students to be more effective and successful in their L2 learning. 


\section{REFRENCES}

Abu-Assali, M.J. (2005) The learning styles of female students in a UAE secondary school. Unpublished (MA) Thesis. Sheffield: The University of Sheffield.

Afitska, O. (2012) Personal Communication. Sheffield: The University of Sheffield.

Castro, O. and Peck, V. (2005) Learning styles and foreign language learning difficulties. Foreign Language Annals, 38(3), 401-409.

Coffield, F. et al. (2004) Learning styles and pedagogy in post-16 learning: A systematic and critical review. London: Learning and Skills Research Centre. Pdf retrieved from

http://lerenleren.nu/bronnen/Learning\%20styles\%20by\%20Coffield\%20e.a..pdf

Cohen A.D. and Weaver, S.J. (2005)Styles and strategies-based instruction: A teachers' guide.Revised version ofCARLA (Working Paper Series \#7.University ofMinnesota: Centre for Advanced Research on Language Acquisition.

Dörnyei, Z. (2005) The psychology of the language learner: Individual differences in second language acquisition. Mahwah, New Jersey; London: Lawrence Erlbaum Associates.

Ehrman, M. and Oxford, R. (1990) Adult language learning styles and strategies in an intensive training setting. The Modern Language Journal, 74(3), 311-327.

Ehrman, M.E. et al. (2003) A brief overview of individual differences in second language learning. System, 31(3), 313-330.

Flowerdew, J. and Shehadeh, A. (2008)Learning styles and performance in second languagetasks. TESOL Quarterly, 42(4), 665-674.

Ford, N., and Chen, S.Y. (2001) Matching/mismatching revisited: An empirical study of learning and teaching styles. British Journal of Educational Technology, 32(1), 5-22.

Hawk, T. and Shah, A. (2007) Using learning style instruments to enhance student learning. Decision Sciences Journal of Innovative Education, 5(1), 1-19.

Hedge, T. (2000) Teaching and learning in the language classroom. Oxford: Oxford University Press.

Hayes, J. and Allinson, C.W. (1996) The implications of learning styles for training and development: A discussion of the matching hypothesis. British Journal of Management, 7(1), 63-73.

Kara, S. (2009). Learning styles and teaching styles: A case study in foreign language classroom. State of the art. Conference of the International Journal of Arts and Sciences, 1(20), 77-82.

Kozhevnikova, E. (2014) Exposing students to authentic materials as a way to increase

students' language proficiency and cultural awareness. Procedia - Social and Behavioral Sciences, 116. $4462-4466$.

Mortimore, T. (2003) Dylexia and learning style: A practitioner's handbook. London and Philadelphia: Whurr.

Oxford, R.L. (2001) Language learning styles and strategies. In: Celce-Murcia, M. (ed.),

Teaching English as a second or foreign language ( ${ }^{\text {rd }}$ ed.). Boston; London: Heinle \& Heinle, pp.359-366.

Pashler, H. et al. (2009) Learning styles: Concepts and evidence. Psychological Science in the Public Interest, 9(3), 105-119. 
Pask, B.G. (1976) Styles and strategies of learning. British Journal of Educational Technology, 46(2), 128-148.

Peacock, M. (2001) Match or mismatch? Learning styles and teaching styles in EFL. International Journal of Applied Linguistics, 11(1), 1-20.

Pritchard, A. (2008) Ways of learning: Learning theories and learning styles in the classroom. London: David Fulton.

Reid, G. (2005) Learning style and inclusion. London: Paul Chapman.

Reid, J.M. (1987) The learning style preferences of ESL students. TESOL Quarterly, 21(1), 87-111.

Sadler-Smith, E. (2001). A reply to Reynolds's critique of learning style. Management Learning, 32(3), 291-304.

Sahragard, R., Mallahi, O. (2014) Relationship between Iranian EFL Learners' Language Learning Styles, Writing Proficiency and Self-assessment, Procedia - Social and Behavioral Sciences 98. 1611-1620.

Scott, C. (2010) The enduring appeal of 'learning styles'. Australian Journal of Education,54(1), 5-17.

Snow, R.E, Carno, L., Jackson III, D. (1996) Individual differences in affective and cognitivefunctions. In: Berliner, D.C., \& Calfee, R.C. (eds.), Handbook of educational psychology. New York, London: Macmillan Library Reference USA; Prentice Hall International, pp.243-310.

Spolsky, B. (1989) Conditions for second language learning. Oxford: Oxford University Press.

Valeo, A. (2000) An investigation into the learning styles of engineers studying English as a second language. Unpublished (MA) dissertation. Sheffield: The University of Sheffield.

Van Zwanenberg, N. Wilkinson, L.J, \& Anderson, A. (2000) Felder and Silverman's index of learning styles and Honey and Mumford's learning styles questionnaire: How dothey compare and do they predict academic performance? Educational Psychology, 20(3), 365-380.

Williamson, M. \& Watson, R. (2006) Learning styles research: Understanding how teaching should be impacted by the way learners learn. Part II: Understanding how learners prefer to receive information. Christian Education Journal, 3(2), 343-361.

Zhou, M. (2011) Learning styles and teaching styles in college English teaching. International Education Studies, 4(1), 73-78. 